\title{
The new Nelson Mandela Children's Hospital - a white elephant or an essential development for paediatric care in Johannesburg?
}

In December 2016, the new Nelson Mandela Children's Hospital (NMCH) was opened by the minister of health, Dr Aaron Motsoaledi, on the University of the Witwatersrand's (Wits) Education Campus across the road from Charlotte Maxeke Johannesburg Academic Hospital in which one of the three clinical academic Departments of Paediatrics attached to Wits is located. Although it has yet to admit its first patient, the new hospital is impressively equipped with wonderful state-of-the-art facilities for both sick children and their parents (cf. editorial in this issue of SAJCH).

A children's hospital is not a novel venture for Johannesburg. Those white paediatricians who trained in Johannesburg before the opening of the new Johannesburg Academic Hospital (now the Charlotte Maxeke Johannesburg Academic Hospital) in 1978 will probably remember with considerable fondness and nostalgia the Transvaal Memorial Hospital for Children (TMH) and its associated Queen Victoria Maternity Hospital just north of the Johannesburg Fort in Hillbrow. This 112-bed hospital was opened in 1923, following a decision in 1919 by the National Council of Women to raise funds to build the hospital to commemorate those South Africans who were killed in World War 1. TMH was thus built and opened some 33 years before the Red Cross War Memorial Children's Hospital in Cape Town in 1956. Many paediatricians mourned the closure of TMH in 1978/9 and the move of paediatric facilities, both medical and surgical, into the then recently completed Johannesburg Academic Hospital, to become lost in a 1000 -bed general hospital.

There is no doubt that sick children need facilities which are very different from those required by adults. The ambience of the hospital should be different, the facilities should be child friendly and the staff appropriately trained to care for infants, children and adolescents with their very different psychological and physical needs. Why then is there so much discussion around the need for the $\mathrm{NMCH}$ among those caring for children within the three clinical paediatric departments in Johannesburg, when it should be clear that providing scarce skills and facilities for sick children can only benefit the paediatric community?

Those who are concerned about the effect that the $\mathrm{NMCH}$ will have on paediatric care in Johannesburg raise a number of issues, all of which relate to the possible increase in competition for limited resources available for the continued provision of care for children within the province. In this discussion, it should be emphasised that $\mathrm{NMCH}$ will probably have little effect on admission rates and acuity levels of children admitted to the public-sector hospitals as $\mathrm{NMCH}$ will be providing care that is currently frequently unavailable or inadequately provided in the public hospitals.

With the closure of a number of nursing colleges over the last 20 years, provincial hospitals are finding it more and more difficult to attract appropriately trained nurses to care for children, especially in areas requiring technical skills such as ICU, surgical theatres and neonatology. Even in the general paediatric wards, there are insufficient staff, especially at night, to ensure appropriate feeding, monitoring and the provision of medication to admitted children. This nursing shortage within the public hospital sector is aggravated by an increasing demand for skilled staff from private hospitals. It is not just the availability of nursing staff that will likely be affected by the opening of NMHC, but also specialised allied medical disciplines such as radiographers and paediatric and surgical subspecialists, who will be attracted from the currently under-resourced provincial hospitals to $\mathrm{NMCH}$ with its state-ofthe-art equipment and facilities.

A further concern that has been raised is the challenge of funding the operational costs of the hospital. It is one thing to raise funds through donations to build and equip the hospital, but it is quite another to consistently raise the necessary funds to keep the ship afloat. It has been suggested that with its developing reputation, $\mathrm{NMCH}$ could attract sufficient numbers of privately funded patients to subsidise the treatment of public-sector children requiring care in a quaternary hospital. Further, the national minister of health has made it clear that the hospital is a national resource and therefore will be funded from the national purse. However, as has very recently been highlighted by the tragedy associated with the closure of psychiatric facilities in Gauteng, provincial funds available to care appropriately for the province's steadily growing population (now estimated at 13.4 million) are insufficient. The concern of many paediatricians is the effect that the funding of NMHC operating costs from the provincial budget will have on the already tight budget allocated to the three academic teaching hospitals. Will the opening of a highly specialised quaternary hospital reduce the province's ability to care for its sick children requiring less technically advanced facilities in secondary and tertiary hospitals?

It is important that we applaud the Nelson Mandela Children's Fund in having the foresight to champion the building of a quaternary care children's hospital in the most populous and wealthiest province in South Africa. I have no doubt that over the coming years it will define its own role in the province's attempt to provide an holistic approach to the care of its children. In the meantime, we should develop services carefully and slowly in the $\mathrm{NMCH}$ so that the services currently provided in the secondary and tertiary hospitals are not destabilised. Further, the provision of a state-of-the-art children's hospital does not relieve the state of its responsibility to upgrade the staffing and facilities at key hospitals such as Chris Hani Baragwanath Academic Hospital, which should not be allowed to physically deteriorate even further.

\author{
John M Pettifor \\ MB BCh, FCPaed (SA), PhD (Med), MASSAf \\ Editor, South African Journal of Child Health \\ john.pettifor@wits.ac.za
}

S Afr J Child Health 2017;11(1):4. DOI:10.7196/SAJCH.2017.v1111.1356 